УДК 543.544.943.3.068.7:577.19:582.998.2

\title{
КОЛИЧЕСТВЕННЫЙ АНАЛИЗ ФЛАВОНОИДОВ В ЦВЕТКАХ РОМАШКИ AПTЕЧНОЙ (MATRICARIA CHAMOMILLA L.) MЕTОДОМ МИкРОКОЛОНОЧНОЙ ВЭЖХ-УФ
}

\author{
(C) Н.И. Кащенко*, Д.Н. Оленников \\ Институт общей и экспериментальной биологии СО РАН, ул. Сахьяновой, 6 , \\ Улан-Удэ, 670047 (Россия), e-mail: ninkk@mail.ru
}

Разработана методика количественного определения флавоноидов в цветках M. chamomilla методом микроколоночной обращенно-фазовой ВЭЖХ с УФ-детектированием (330 нм) с применением сорбента ProntoSIL-120-5-C18 $\mathrm{AQ}\left(60\right.$ мм $\times 1$ мм $\times 5$ мкм) и градиентной элюентной системы $0,2 \mathrm{M} \mathrm{LiClO}_{4} / 0,006 \mathrm{M} \mathrm{HClO}_{4}$-ацетонитрил. Космосиин был выбран в качестве вещества сравнения. Подобраны оптимальные условия для осуществления гидролитического процесса флавоноидов (концентрация $\mathrm{KOH}$ в смеси 0,25\%, время контакта фаз 30 мин) и параметры экстракции флавоноидов (степень измельчения сырья $0,25 \mathrm{mм}$, температура экстракции $60{ }^{\circ} \mathrm{C}$, однократная экстракция длительностью 30 мин при соотношении сырье : экстрагент $1: 100)$. Валидационный анализ показал, что методика характеризуется удовлетворительными метрологическими показателями. Предел детектирования (LOD), предел количественного определения (LOQ) космосиина составили 84 и 255 нг/мл соответственно. Показатели точности для уровней содержания космосиина $80-120 \%$ не превышали 101,93-103,00\%. Методика была применена для анализа интродуцированных и коммерческих образцов сырья M. chamomilla.

Ключевые слова: Matricaria chamomilla L., Asteraceae, космосиин, флавоноиды, микроколоночная ВЭЖХ-УФ.

Работа выполнена при поддержке проекта СО РАН № VI.62.1.8.

\section{Введение}

Matricaria chamomilla L. (ромашка аптечная) - известное растение семейства Asteraceae, имеющее многолетний опыт применения в официнальной медицине большинства стран мира. Данный растительный вид относится к числу многотоннажного культивируемого сырья, занимающего по площади выращивания первое место [1].

Наукометрические исследования свидетельствуют о постоянно растущем интересе к изучению $M$. chamomilla со стороны ученых различных областей - биологов, фармакологов, фитохимиков и других. Анализ данных литературы о химическом составе данного вида свидетельствует о его разнообразии; известно о присутствии кумаринов [2], фенилпропаноидов [3, 4], флавоноидов [5-7], полииновых соединений $[8,9]$, полисахаридов $[10,11]$ и эфирного масла [12]. Данный растительный вид обладает широким спектром биологической активности, вызванной в большинстве случаев присутствием фенольных соединений. В частности было установлено, что противовоспалительная $[13,14]$ и спазмолитическая активность M. chamomilla обусловлены преимущественно флавоноидами [15, 16$]$.

В России разрешенным к применению видом лекарственного сырья M. chamomilla являются «Цветки ромашки» [17]. Нормативный документ, принятый в XX в., включает рекомендацию о количественной

Кащенко Нина Игоревна - кандидат фармацевтических наук, младший научный сотрудник лаборатории медикобиологических исследований, e-mail: ninkk@mail.ru

Оленников Даниил Николаевич - доктор

фармацевтических наук, ведущий научный сотрудник лаборатории медико-биологических исследований, e-mail: olennikovdn@mail.ru стандартизации сырья по содержанию эфирного масла. Близким к данному варианту количественной стандартизации сырья M. chamomilla является метод, включенный в Государственную фармакопею Республики Беларусь [18]. Европейские фармакопеи и фармакопеи республики Казахстан и США ис-

\footnotetext{
* Автор, с которым следует вести переписку.
} 
пользуют метод ВЭЖХ для количественного анализа флавоноидов в M. chamomilla $[19,20]$. Часто применяемым методом количественного анализа флавоноидов в цветках M. chamomilla является дифференциальная спектрофотометрия спиртового извлечения с последующим пересчетом результатов в эквивалентах рутина $[21,22]$. Учитывая важность количественного анализа флавоноидов, некоторые авторы предлагают различные варианты хроматографического анализа, в том числе ВЭЖХ-УФ, ВЭЖХ-МС, УВЭЖХ-МС (табл. 1). Недостатками известных методов являются значительный расход элюента (100-300 мл/анализ) и продолжительное время анализа (25-90 мин). Кроме того, данные методики разработаны для импортных моделей хроматографов.

В последнее время большим интересом пользуется метод микроколоночной ВЭЖХ (МК-ВЭЖХ), к числу преимуществ которого относятся экспрессность, экономичность и удовлетворительные метрологические показатели. Кроме того, расширение возможностей применения МК-ВЭЖХ сделает анализ действующих веществ в $M$. chamomilla более доступным. Целью настоящего исследования является разработка простого и эффективного метода количественного определения флавоноидов в цветках M. chamomilla с применением обращенно-фазовой МК-ВЭЖХ с УФ-детектированием.

Таблица 1. Известные методы ВЭЖХ анализа флавоноидов M. chamomilla

\begin{tabular}{|c|c|c|c|c|}
\hline Метод & Соединение & Колонка & Мобильная фаза & $\begin{array}{c}\text { Время } \\
\text { анализа, } \\
\text { мин }\end{array}$ \\
\hline ВЭЖХ-УФ [23] & $\begin{array}{l}\text { Апигенин, космосиин, апигенин- } \\
\text { 7-O-(2"-Ac)-Glcp }\end{array}$ & $\begin{array}{c}\text { ODS Sil-X } \\
(250 \text { мм } \times 5 \text { мкм } \times 2,6 \text { мкм })\end{array}$ & $\begin{array}{c}2 \% \mathrm{CH}_{3} \mathrm{COOH} \text { в } \mathrm{H}_{2} \mathrm{O} \\
\text { (A), } \mathrm{MeCN} \text { (B) }\end{array}$ & 25 \\
\hline ВЭЖХ-УФ [24] & Апигенин, космосиин & $\begin{array}{c}\text { NovaPak C18 } \\
(150 \text { мм } \times 3,9 \text { мм } \times 4 \text { мкм })\end{array}$ & $\mathrm{H}_{2} \mathrm{O}(\mathrm{A}), \mathrm{MeCN}(\mathrm{B})$ & 25 \\
\hline ВЭЖХ-УФ [25] & $\begin{array}{l}\text { Гиперозид, изокверцитрин, кос- } \\
\text { мосиин апигенин-7-O-(2"-Ac)- } \\
\text { Glc } p \text {, цинарозид, }\end{array}$ & $\begin{array}{c}\text { Zorbax 300SB-C18 } \\
(150 \mathrm{Mм} \times 2,1 \mathrm{Mм} \times 5 \mathrm{MKм})\end{array}$ & $\begin{array}{l}0,1 \% \mathrm{HCOOH} \text { в } \mathrm{H}_{2} \mathrm{O} \\
\text { (A), } \mathrm{MeCN} \text { (B) }\end{array}$ & 90 \\
\hline ВЭЖХ-МС [26] & $\begin{array}{l}\text { Изокверцитрин, кверцимеритрин, } \\
\text { апигенин, космосиин, апигенин- } \\
\text { 7-O-(2"-Ac)-Glcp, апигенин-7-O- } \\
\text { (6"-Ac)-Glcp, лютеолин-4'-O- } \\
\text { Glcp, сколимозид, патулитрин }\end{array}$ & $\begin{array}{c}\text { Inertsil ODS-3 } \\
(150 \mathrm{Mм} \times 3,0 \mathrm{Mм} \times 3 \mathrm{м \kappa м})\end{array}$ & $\begin{array}{c}0,1 \% \mathrm{CF}_{3} \mathrm{COOH} \text { в } \\
\mathrm{H}_{2} \mathrm{O}(\mathrm{A}), \mathrm{MeCN}(\mathrm{B})\end{array}$ & 50 \\
\hline ВЭЖХ-МС [27] & $\begin{array}{l}\text { Апигенин, космосиин, изороифо- } \\
\text { лин, }\end{array}$ & $\begin{array}{c}\text { ODS-AQ } \\
(150 \text { мм } \times 3 \text { мм } \times 5 \text { мкм })\end{array}$ & $\begin{array}{l}0,01 \% \text { HCOOH в } \mathrm{H}_{2} \mathrm{O} \\
\text { (A), } \mathrm{MeCN} \text { (B) }\end{array}$ & 35 \\
\hline $\begin{array}{l}\text { УВЭЖХ-УФ } \\
{[28]}\end{array}$ & $\begin{array}{l}\text { Апигенин, космосиин, кверцетин, } \\
\text { рутин, изорамнетин, лютеолин, } \\
\text { кемпферол }\end{array}$ & $\begin{array}{c}\text { Blue Orchid C18 } \\
(150 \mathrm{Mм} \times 2 \mathrm{Mм} \times 1,8 \mathrm{м \kappa м})\end{array}$ & $\begin{array}{c}4 \% \mathrm{CH}_{3} \mathrm{COOH} \text { в } \mathrm{H}_{2} \mathrm{O} \\
\text { (A), } \mathrm{MeCN} \text { (B) }\end{array}$ & 35 \\
\hline $\begin{array}{l}\text { УВЭЖХ-МС/MC } \\
{[29]}\end{array}$ & $\begin{array}{l}\text { Кверцетин, изокверцитрин, ру- } \\
\text { тин, кверцитрин, изорамнетин, } \\
\text { апигенин, космосиин, лютеолин, } \\
\text { кемпферол }\end{array}$ & $\begin{array}{c}\text { Acquity BEH C18 } \\
(100 \mathrm{Mм} \times 2,1 \mathrm{Mм} \times 1,7 \text { мкм })\end{array}$ & $\begin{array}{c}0,1 \% \text { HCOOH в } \\
\mathrm{MeOH}(\mathrm{A}), \mathrm{MeCN}(\mathrm{B})\end{array}$ & 35 \\
\hline
\end{tabular}

\section{Экспериментальная часть}

Paстительное сырье. Образцы M. chamomilla (сорт «Подмосковная») были выращены в открытом грунте на экспериментальных плантациях ИОЭБ СО РАН (2014-2015 гг.) из аутентифицированных семян, полученных в Главном ботаническом саду им. Н.В. Цицина РАН (Москва, Россия). Для культивирования были использованы рекомендованные для M. chamomilla агротехнические условия [30]. Сбор цветков проводили в фазу массового цветения. Образцы сырья хранятся в гербарии ИОЭБ СО РАН. Коммерческое сырье было приобретено через аптечную сеть.

Общие экспериментальные условия. Исследования проводили на микроколоночном жидкостном хроматографе «Милихром А-02» («Эконова»), снабженным автосемплером, УФ-детектором и стальной колонкой (60 мм × 1 мм). В работе использовали ацетонитрил (НПК «Криохром», Россия; сорт 0), $\mathrm{LiClO}_{4}$, $\mathrm{HClO}_{4}$, воду для ВЭЖХ Chromasolv, космосиин (Sigma, Switzerland); остальные реагенты имели чистоту ч.д.а. В качестве референтных веществ использовали коммерчески доступные соединения (космосиин), а также соединения, выделенные нами ранее из цветков M. chamomilla [31]. 
ВЭЖХ. Неподвижная фаза ProntoSIL-120-5-C18 AQ (5 мкм; Metrohm AG). Подвижная фаза: 0,2 M $\mathrm{LiClO}_{4}$ в 0,006 $\mathrm{M} \mathrm{HClO}_{4}(\mathrm{~A}), \mathrm{MeCN}(\mathrm{B})$; градиентный режим (\%B): 0,00-1,50 мин 5-25\%, 1,50-2,75 мин $25 \%, 2,75$ мин 25-30\%, 2,75-4,25 мин 30-60\%, 4,25 мин 60-100\%, 4,25-5,00 мин 100\%; скорость элюирования 600 мкл/мин; температура колонки $35^{\circ} \mathrm{C}$; спектрофотометрический детектор: длина волны 330 нм.

Методика количественного анализа космосиина в цъветках M. chaтотіlla методом ВЭЖХ. Аналитическую пробу сырья измельчают до размера частиц, проходящих сквозь сито с отверстиями диаметром 0,25 мм. Около 50 мг (точная навеска) измельченного сырья помещают в пластиковую пробирку вместимостью 10 мл, прибавляют 5 мл 80\% этанола и экстрагируют в ультразвуковой бане при $60{ }^{\circ} \mathrm{C}$ в течение 30 мин. Охлаждают, центрифугируют при 3000 об/мин в течение 5 мин, переносят в мерную колбу на 5 мл и доводят до метки 80\% этанолом (раствор А). 500 мкл раствора А переносят в пробирку Эппендорф вместимостью 1 мл и приливают 50 мкл 2,5\% раствора гидроксида калия. Через 30 мин к извлечению приливают 50 мкл уксусной кислоты, раствор центрифугируют при 3000 об/мин. Надосадочную жидкость фильтруют через мембранный фильтр с диаметром пор 0,45 мкм (раствор Б) и 1 мкл используют для анализа методом ВЭЖХ в описанных ранее условиях. 1 мкл раствора Б вводят в жидкостной хроматограф «Милихром А-02» с УФ-детектором и хроматографируют, как указано выше.

Содержание космосиина $(X)$ в процентах рассчитывают по формуле:

$$
X=\frac{S \cdot K^{V} \cdot m_{c m}}{S_{c m} \cdot m \cdot K_{c m}^{V}} \cdot \frac{100}{100-W} \cdot 100
$$

где $S$ - площадь пика космосиина на хроматограмме исследуемого раствора; $S_{c m}$ - площадь пика космосиина на хроматограмме раствора стандартного образца; $K^{V}$ - коэффициент разбавления исследуемого раствора (6); $K_{c m}^{V}$ - коэффициент разбавления стандартного раствора (1); $m$ - масса навески сырья, г; $m_{c m}-$ масса навески космосиина; $W$ - потеря в массе при высушивании сырья, \%.

Приготовление раствора стандартного образца космосиина. 5,0 мг космосиина переносят в мерную колбу на 5 мл, растворяют в 80\% этаноле и доводят до объема 5 мл этим же растворителем.

Валидационный анализ проводился согласно рекомендациям [32]. Для построения градуировочного графика серию разведений космосиина (1,836-940 мкг/мл) хроматографировали в описанных выше условиях трижды для каждой концентрации вещества. По полученным данным проводили построение градуировочного графика в координатах «концентрация, мкг/мл - площадь пика» и определяли вид уравнения линейной регрессии $(Y=a X+b)$, значения коэффициента детерминации $\left(r^{2}\right)$ и стандартного отклонения $\left(S_{Y X}\right)$ с применением пакета программ Advanced Grapher ver. 2.2 (Alentum Software, Inc., США). Предел детектирования (LOD) и предел количественного определения (LOQ) определяли по уравнениям: LOD = $\left(3,3 \mathrm{~S}_{\mathrm{YX}}\right) / \mathrm{a}$ и $\mathrm{LOQ}=\left(10 \mathrm{~S}_{\mathrm{YX}}\right) / \mathrm{a}$, где $S_{Y X}-$ стандартное отклонение, $a-$ коэффициент при X в уравнении линейной регрессии. Для определения воспроизводимости серию стандартных растворов космосиина (235 мкг/мл) анализировали в трехкратной повторности. Вариабельность методики определяли в двух вариантах: «день-в-день» (intra-day) и «день-через-день» (inter-day). В первом варианте стандартный раствор космосиина (235 мкг/мл) анализировали в течение дня шестикратно, во втором варианте анализа стандартный раствор космосиина анализировали в течение трех последовательных дней трехкратно. Стабильность методики определяли на одном образце цветков M. chamomilla (интродукция, сорт «Подмосковная», серия 072014), анализируя его через 2, 4, 8, 12, 24 и 72 ч после первого анализа. Показатель точности методики выявляли на образце цветков M. chamomilla (интродукция, сорт «Подмосковная», серия 072014) с введением в навеску референтного вещества космосиин в количестве 80-120\% от исходного содержания с последующими экстракцией и анализом. В качестве показателя эффективности методики при определении вариабельности, воспроизводимости, стабильности и точности использовали величину относительного стандартного отклонения RSD: RSD $=\left(100 \cdot S_{x i}\right) / \bar{x}$, где $S_{x i}$ - стандартное отклонение $x_{i}, \bar{x}-$ среднее значение $x$.

\section{Обсуждение результатов}

Многокомпонентность химического профиля цветков M. chamomilla, интродуцированной в Восточной Сибири, была показана нами ранее [31]. Основными составляющими M. chamomilla являются космосиин и его производные [апигенин-7-O-(4"-малонил)-глюкопиранозид, апигенин-7-O-(6"-малонил)-глюкопиранозид, 
апигенин-7-O-(4"'-ацетил)-глюкопиранозид, апигенин-7-O-(4"-ацетил-6"-малонил)-глюкопиранозид, апигенин-7-O-(4"-малонил-6"-ацетил)-глюкопиранозид], фенилпропаноиды (3-O- и 3,5-ди-O-кофеилхинные кислоты, 2-O-глюкопиранозиды изис- и транс-2-гидрокси-4-метоксикумаровой кислоты), кумарины (скиммин, дафнетин, дафнин, умбеллиферон, герниарин), а также терпены (цис- и транс-спироэфир) (рис. 1А).

Производные апигенина - доминирующие соединения цветков M. chamomilla и являются маркерной группой соединений для данного вида растительного сырья. Однако хроматографический анализ нативных образцов M. chamomilla сопряжен с рядом трудностей, включая отсутствие референтных веществ и неустойчивость дериватов космосиина. В этой связи целесообразным является выбор одного или нескольких референтных соединений, количественное содержание которых свидетельствует о качестве растительного сырья. Основным флавоноидом цветков ромашки является апигенин-7-O-(4"-ацетил-6"-малонил)глюкопиранозид, содержание которого может составлять более 4\% от массы воздушно-сухого сырья (данные не представлены). Несмотря на высокое содержание данного соединения стандартизация цветков M. chamomilla по данному компоненту затруднена вследствие отсутствия образца сравнения. Коммерчески доступным производным апигенина является апигенин-7-O-глюкопиранозид (космосиин), присутствующий в растительном сырье, однако в меньших концентрациях.

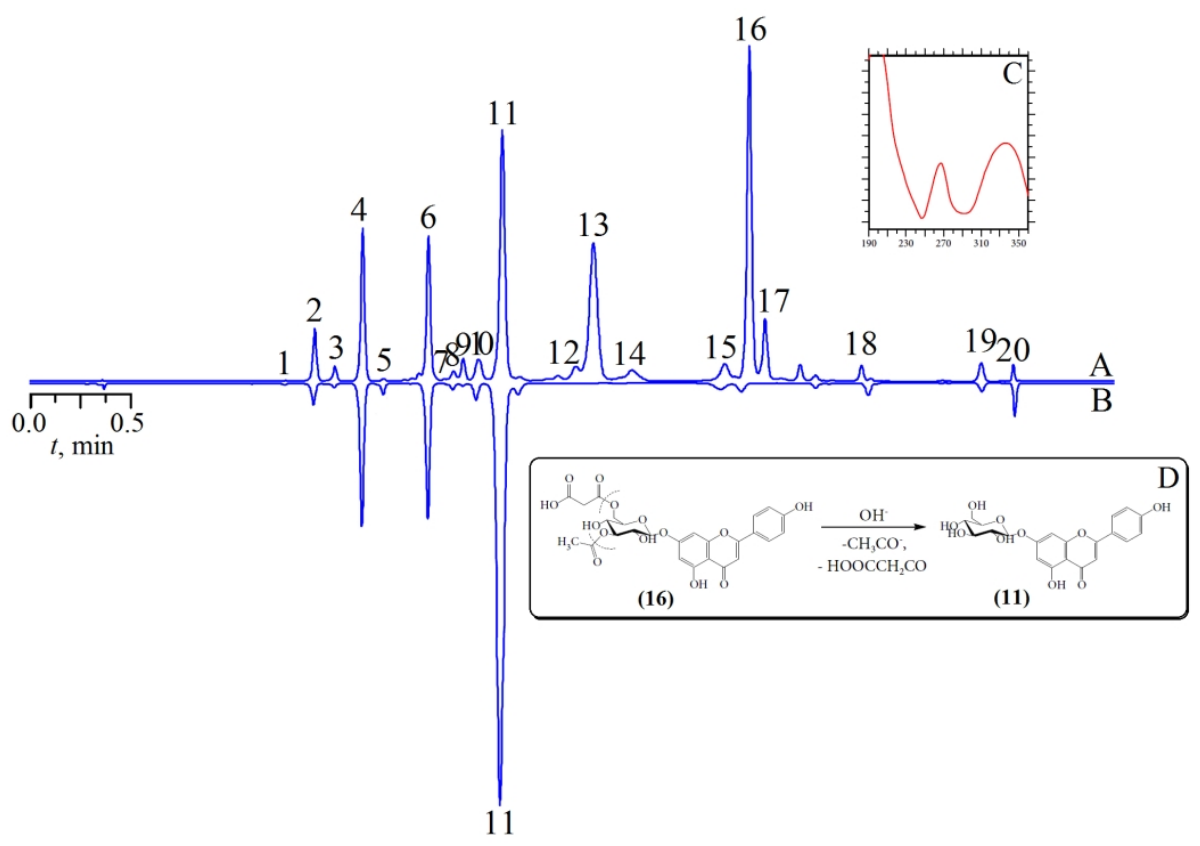

Хроматограммы (МК-ВЭЖХ-УФ) спиртового извлечения из цветков M. chamomilla до (А) и после щелочного гидролиза (В) (цветной вариант рисунка доступен в электронной версии журнала). Числами обозначено положение соединений: 1 - скиммин (умбеллиферон-7-O-глюкопиранозид), 2 - дафнин (дафнетин-7-O-глюкопиранозид), 3 - 3-O-кофеилхинная кислота, 4 - циис-2-гидрокси-4-метоксикумаровой кислоты 2-O-глюкопиранозид, 5 - дафнетин, 6 - транс-2-гидрокси-4-метоксикумаровой кислоты 2-Oглюкопиранозид, 7 - умбеллиферон, 8 - цинарозид (лютеолин-7-O-глюкопиранозид), 9 - 3,5-ди-Oкофеилхинная кислота, 10 - кумарин (не идентифицирован), 11 - космосиин (апигенин-7-Oглюкопиранозид), 12 - апигенин-7-O-(4"-малонил)-глюкопиранозид, 13 - апигенин-7-O-(6"-малонил)глюкопиранозид, 14 - апигенин-7-O-(4"-ацетил)-глюкопиранозид, 15 - герниарин, 16 - апигенин-7-O-(4"ацетил-6"-малонил)-глюкопиранозид, 17 - апигенин-7-O-(4"-малонил-6"-ацетил)-глюкопиранозид, 18 апигенин, 19 - циис-спироэфир (Z-ен-ин-бициклоэфир), 20 - транс-спироэфир ( $E$-ен-ин-бициклоэфир). На врезках: C - спектр поглощения соединений 11-17; D - схема распада соединения 16.

Для «упрощения» химического состава нативного извлечения целесообразным является использование свойства ацилированных производных космосиина к необратимой потере ацильных групп в щелочной среде (рис. 1D). Данный принцип использован в методике количественного анализа цветков M. chamomilla в Европейской фармакопее (EPh 7.0), которая рекомендует осуществление щелочного гидролиза с 8,5\% $\mathrm{NaOH}$ на кипящей водяной бане в течение 1 ч [33]. В этой связи возникает вопрос о необходимости ис- 
пользования столь жестких условий. Согласно сведениям научной литературы, ацилированные производные апигенина являются лабильными соединениями [34] и распадаются до агликона под воздействием высокой температуры во время экстракции $[35,36]$, тогда как при расчете содержания флавоноидов в сырье по методике EPh 7.0 в качестве вещества сравнения используется гликозид космосиин. Кроме того, данный метод отличается трудоемкостью, длительностью процедуры и большим расходом химических реагентов.

Для устранения недостатков известного метода были подобраны оптимальные параметры процесса гидролиза гликозидов. Для проведения процедуры гидролиза было исследовано влияние различных концентраций гидролитического агента $(0,05-1 \% \mathrm{KOH})$ и длительности процесса гидролиза (15-180 мин). Низкие концентрации щелочи не позволяли осуществлять полное дезацилирование за короткий промежуток времени, в то время как при высоких концентрациях КОН наблюдался процесс необратимой деструкции космосиина. Оптимальные условия для проведения гидролиза были следующие: концентрация КОН в смеси 0,25\%, время контакта фаз 30 мин. Правильность выбора условий для гидролиза подтверждалась результатами хроматографического анализа: после гидролиза в рабочем растворе обнаруживался только космосиин; ацилированные производные апигенина отсутствовали (рис. 1Б). Таким образом, выбранные параметры гидролиза могут быть использованы для процесса подготовки растительного извлечения к дальнейшему хроматографическому анализу.

Для осуществления анализа методом ВЭЖХ в качестве неподвижной фазы был выбран обращенофазовый сорбент ProntoSIL-120-5-C18 AQ, а также градиентный режим элюирования с применением системы растворителей, состоящей из $\mathrm{LiClO}_{4} / \mathrm{HClO}_{4}$ и ацетонитрила. Замена ацетонитрила метанолом приводила к неудовлетворительному разделению соседних пиков. Применение изократического режима элюирования приводило к пролонгированию времени анализа и недостаточной остроте пиков на хроматограммах. Было установлено, что более качественное разделение фенольных соединений происходило при температуре колонки $35^{\circ} \mathrm{C}$. Длинноволновый максимум поглощения космосиина (330 нм) был выбран в качестве рабочей длины волны детектора (рис. 1C). Время хроматографического анализа одной пробы составило 5,5 мин. Итоговая хроматограмма содержала доминирующий пик космосиина, а также несколько минорных пиков нефлавоноидных соединений, что позволило использовать выбранные условия для дальнейшего анализа.

Необходимым условием для любой методики количественного анализа являются оптимальные параметры процесса экстракции флавоноидов, обеспечивающие их максимальное извлечение, включая тип экстрагента, температуру экстракции, степень измельчения сырья, соотношение «сырье - экстрагент», кратность и время экстракции.

В результате было установлено, что наиболее эффективная экстракция флавоноидов наблюдается для степени измельчения сырья 0,25 мм, температуры экстракции $60{ }^{\circ} \mathrm{C}$, однократной экстракции длительностью 30 мин при соотношении сырье : экстрагент 1 : 100 (табл. 2).

Таблица 2. Влияние технологических параметров на выход флавоноидов

\begin{tabular}{|c|c|c|c|}
\hline Параметр & Флавоноиды, мкг/мл & Параметр & Флавоноиды, мкг/мл \\
\hline \multicolumn{2}{|c|}{ Экстрагент (концентрация этанола, \%) } & \multicolumn{2}{|c|}{ Соотношение сырье : экстрагент } \\
\hline 20 & $108,23 \pm 2,48$ & $1: 10$ & $197,34 \pm 3,75$ \\
\hline 40 & $156,04 \pm 2,81$ & $1: 25$ & $223,52 \pm 4,02$ \\
\hline 60 & $241,12 \pm 4,58$ & $1: 50$ & $240,03 \pm 4,56$ \\
\hline 80 & $269,31 \pm 5,39$ & $1: 100$ & $273,11 \pm 5,19$ \\
\hline 93 & $114,28 \pm 2,17$ & $1: 200$ & $264,25 \pm 5,29$ \\
\hline \multicolumn{2}{|c|}{ Температура, ${ }^{\circ} \mathrm{C}$} & \multicolumn{2}{|c|}{ Степень измельчения, мм } \\
\hline 40 & $271,09 \pm 4,88$ & $<1,00$ & $96,18 \pm 1,83$ \\
\hline 50 & $273,45 \pm 5,47$ & $<0,50$ & $268,33 \pm 5,37$ \\
\hline 60 & $280,65 \pm 4,77$ & $<0,25$ & $279,10 \pm 5,30$ \\
\hline 70 & $273,41 \pm 4,37$ & & \\
\hline \multicolumn{4}{|c|}{ Время и кратность экстракции } \\
\hline \multirow{2}{*}{ Время, мин } & \multicolumn{3}{|c|}{ Экстракция } \\
\hline & $\mathrm{I}$ & II & III \\
\hline 15 & $208,14 \pm 3,75$ & $17,10 \pm 0,27$ & $7,04 \pm 0,11$ \\
\hline 30 & $267,09 \pm 5,07$ & $19,14 \pm 0,38$ & $3,01 \pm 0,05$ \\
\hline 45 & $269,23 \pm 4,85$ & $13,26 \pm 0,25$ & $2,09 \pm 0,04$ \\
\hline 60 & $268,25 \pm 4,83$ & $19,08 \pm 0,38$ & $4,01 \pm 0,06$ \\
\hline 75 & $251,51 \pm 5,03$ & $18,31 \pm 0,37$ & $3,27 \pm 0,06$ \\
\hline
\end{tabular}


Валидационный анализ показал, что зависимость площади хроматографического пика от концентрации космосиина в диапазоне концентрации 1-1000 мкг/мл описывалась линейной регрессией со значением коэффициента детерминации 0,9999 (табл. 3). Величины пределов детектирования (LOD) и количественного определения космосиина (LOQ) составили 84 и 255 нг/мл соответственно. Показатели воспроизводимости, вариабельности и стабильности не превышали 1,5\%, а точность методики, определенная для пяти уровней концентрации (80-120\%), составила 101,93-103,00\% (табл. 4). Полученные результаты свидетельствуют об удовлетворительных метрологических характеристиках разработанной методики.

Разработанная методика была апробирована на пяти коммерческих и двух интродуцированных образцах сырья. Результаты количественного анализа показали, что содержание космосиина в исследованном сырье составило 0,20-1,26\% (табл. 5). Применение метода EPh 7.0 для анализа тех же партий сырья выявило занижение результатов на 15-20\% от таковых, полученных с использованием разработанной методики. Вероятной причиной данного недостатка является многостадийность метода $\mathrm{EPh} 7.0$, приводящая к высокой относительной ошибке определения $(\Delta E)$ 6,25-9,68\%, превышающей рекомендованный показатель в 5\%.

Таблица 3. Валидационные параметры разработанной методики

\begin{tabular}{l|c}
\hline \multicolumn{1}{c|}{ Показатель } & Значение \\
\hline Уравнение регрессии & $Y=0,030 \cdot X+0,001^{*}$ \\
Коэффициент детерминации $\left(\mathrm{r}^{2}\right)$ & 0,9999 \\
Стандартное отклонение $\left(S_{\mathrm{Yx}}\right)$ & $7,69 \cdot 10^{-4}$ \\
Предел детектирования (LOD), нг/мл & 84 \\
Предел количественного определения (LOQ), нг/мл & 255 \\
Рабочий диапазон, мкг/мл & $1-1000$ \\
Воспроизводимость, \% $(n=15)$ & 1,12 \\
Вариабельность «день-в-день», \% $(n=6)$ & 0,77 \\
Вариабельность «день-через-день», \% $(n=9)$ & 0,91 \\
Стабильность, \% $(n=7)$ & 1,05 \\
\hline
\end{tabular}

${ }^{*} X$ - концентрация, мкг/мл; $Y$ - площадь пика.

Таблица 4. Результаты определения точности разработанной методики

\begin{tabular}{l|c|c|c|c|c}
\hline \multicolumn{1}{c|}{ Показатель } & \multicolumn{5}{c}{ Уровень } \\
\cline { 2 - 6 } & $80 \%$ & $90 \%$ & $100 \%$ & $110 \%$ & $120 \%$ \\
\hline Космосиина в сырье, мкг & 460 & 460 & 460 & 460 & 460 \\
Введено космосиина, мкг & 368 & 414 & 460 & 506 & 552 \\
Должно быть космосиина, мкг & 828 & 874 & 920 & 966 & 1012 \\
Найдено космосиина, мкг & 844 & 893 & 941 & 995 & 1039 \\
Точность, \% & 101,93 & 102,17 & 102,28 & 102,38 & 103,00 \\
\hline
\end{tabular}

Таблица 5. Содержание флавоноидов в некоторых партиях сырья M. chamomilla, определенное с применением разработанной методики и по методу $\mathrm{EPh} 7.0$

\begin{tabular}{l|c|c|c|c|c|c|c}
\hline \multicolumn{1}{c|}{ Производитель } & Партия & \multicolumn{2}{|c|}{ Разработанная методика } & \multicolumn{4}{|c}{$\mathrm{EPh} 7.0$} \\
\cline { 3 - 8 } & сырья & $x, \%$ & $\pm \mathrm{SD}$ & $\Delta E, \%$ & $x, \%$ & $\pm \mathrm{SD}$ & $\Delta E, \%$ \\
\hline OAО «Красногорсклексредства» & 032015 & 1,26 & 0,02 & 1,59 & 1,07 & 0,09 & 8,41 \\
$\mathrm{OAO}$ «расногорсклексредства» & 240614 & 0,76 & 0,01 & 1,32 & 0,64 & 0,06 & 9,38 \\
ЗАО «Ст.-Медифарм» & 010114 & 0,29 & 0,00 & 1,70 & 0,24 & 0,02 & 8,33 \\
OOO «ZАМОNA RA'NO» & 030614 & 0,20 & 0,00 & 1,80 & 0,16 & 0,01 & 6,25 \\
OОО «Камелия-ЛТ» & 102014 & 0,38 & 0,01 & 1,70 & 0,31 & 0,03 & 9,68 \\
Интродукция, сорт «Подмосковная» & 072014 & 0,92 & 0,01 & 1,09 & 0,74 & 0,06 & 8,11 \\
& 072015 & 0,84 & 0,01 & 1,19 & 0,67 & 0,06 & 8,96 \\
\hline
\end{tabular}

\section{Выводы}

Цветки M. chamomilla характеризуются сложным химическим профилем. Биологическая активность данного растительного вида обусловлена присутствием фенольных соединений, в частности флавоноидов, среди которых превалируют ацилированные производные апигенина. Большинство нормативных документов рекомендуют проведение количественной стандартизации данного вида растительного сырья по содержанию флавоноидов. Часто применяемым методом количественного анализа флавоноидов в цветках M. chamomilla является ВЭЖХ гидролизованного спиртового извлечения с пересчетом результатов в экви- 
валентах гликозида космосиина. Однако относительно «жесткие» условия гидролиза приводят к распаду космосиина до агликона апигенина и, как следствие, к неправильным результатам анализа. Кроме того, многостадийность метода обусловливает высокую относительную ошибку (более 6\%). Разработанная нами методика количественного анализа космосиина с использованием микроколоночной ВЭЖХ-УФ отличается экспрессностью и удовлетворительными метрологическими параметрами и предлагает оптимальные условия для осуществления гидролитического процесса и хроматографического разделения. Анализ реальных образцов (коммерческих, интродуцированных партий цветков M. chamomilla) подтвердил перспективность применения данной методики в фармацевтической практике.

\section{Список литературы}

1. Куркин В.А., Шарова О.В., Афанасьева П.В., Вельмисева Л.Е., Федоров А.В. Перспективы создания высокопродуктивной сырьевой базы календулы лекарственной // Известия Самарского научного центра РАН. 2012. T. 14. C. 2249-2252.

2. Petruĺová-Poracká V., Repčák M., Vilková M., Imrich J. Coumarins of Matricaria chamomilla L.: aglycones and glycosides // Food Chem. 2013. Vol. 141. Pp. 54-59.

3. Ganzera M., Guggenberger M., Stuppner H., Zidorn C. Altitudal variation of secondary metabolite profiles in flowering heads of Matricaria chamomilla cv. BONA // Planta Med. 2008. Vol. 74. Pp. 453-457.

4. Caleja C., Barros M., Antonoi A.L., Ciric A., Barreira J.C.M., Sokovic M., Oliveira M.B.P.P., Santos-Buelga C., Ferreira I.C.F.R. Development of a functional dairy food: Exploring bioactive and preservation effects of chamomile (Matricaria recutita L.) // J. Funct. Foods. 2015. Vol. 16. Pp. 114-124.

5. Kunde R., Isaak O. Uber die Flavone der Kamille (Matricaria chamomilla L.) und ein Neues Acetyliertes Apigenin7-glucoside // Planta Med. 1979. Vol. 37. Pp. 124-130.

6. Exner J., Reichling J., Becker H. Flavonoide in Matricaria chamomilla // Planta Med. 1980. Vol. 39. Pp. $219-219$.

7. Xie X.-Y., Wang R., Shi Y.-P. Flavonoids from the flowers of Matricaria chamomilla // Chem. Nat. Comp. 2014. Vol. 50. Pp. 910-911.

8. Redaelli C., Santaniello L.F. High-performance liquid chromatography of cis- and trans-en-in-dicyclo ethers (spiro ethers) in Matricaria chamomilla L. flowers and in chamomile extracts // J. Chromatogr. A. 1981. Vol. 209. Pp. 110-112.

9. Glasl H. Simple and fast determination of cis- and trans-spiroether in Matricaria chamomilla using liquid chromatography // J. Chromatogr A. 1975. Vol. 114. Pp. 215-219.

10. Uteshev B.S., Laskova I.L., Afanas'ev V.A. The immunomodulating activity of the heteropolysaccharides from German chamomile (Matricaria chamomilla) during air and immersion cooling // Eksp. Klin. Farmakol. 1999. Vol. 62. Pp. 52-55.

11. Füller E., Blaschek W., Franz G. Characterization of water-soluble polysaccharides from chamomile flowers // Planta Med. 1991. Vol. 57. Pp. 40-40.

12. Rezaeih R.A.P., Gurbuz B., Uyanik M., Rahimi A., Arslan N. Volatile constituents variability in Matricaria chamomilla L. from Ankara, Turkey // J. Essent. Oil Bear. Pl. 2015. Vol. 18. Pp. 255-260.

13. Miguel F.G., Cavalheiro A.H., Spinola N.F., Ribeiro D.L., Barcelos G.R.M., Antunes L.M.G., Hori J.I., MarqueleOliveira F., Rocha B.A., Berretta A.A. Validation of a RP-HPLC-DAD method for chamomile (Matricaria recutita) preparations and assessment of the marker, apigenin-7-glucoside, safety and anti-inflammatory effect // J. Evid. Based Complement. Altern. Med. 2015. Vol. 2015. URL: https://www.ncbi.nlm.nih.gov/pmc/articles/PMC4573433/

14. Li K.-C., Ho Y.-L., Hsieh W.-T., Huang S.-S., Chang Y.-S., Huang G.-J. Apigenin-7-glycoside prevents LPS-induced acute lung injury via downregulation of oxidative enzyme expression and protein activation through inhibition of MAPK phosphorylation // Int. J. Mol. Sci. 2015. Vol. 16. Pp. 1736-1754.

15. Achterrath-Tuckermann U., Kunde R., Flaskamp E., Isaac O., Thiemer K. Pharmacological investigations with compounds of chamomile. V. Investigations on the spasmolytic effect of compounds of chamomile and Kamillosan on the isolated guinea pig ileum // Planta Med. 1980. Vol. 39. Pp. 38-50.

16. Maschi O., Cero E.D., Galli G.V., Caruso D., Bosisio E., Dell'Agli M. Inhibition of human cAMP-phosphodiesterase as a mechanism of the spasmolytic effect of Matricaria recutita L. // J. Agric. Food Chem. 2008. Vol. 56. Pp. 5015-5020.

17. Государственная фармакопея СССР. М., 1990. Вып. 2. С. 237-238.

18. Ромашки цветки. Государственная фармакопея Республики Беларусь. Минск, 2007. Т. ІІ. С. $412-413$.

19. Ромашки цветы. Государственная фармакопея Республики Казахстан. Алматы, 2008. Т. 2.724 с.

20. United States Pharmacopeia. "Dietary supplements-Botanicals". The United States Pharmacopeial Convention, 2007. $901 \mathrm{p}$.

21. Печерская Л.Г., Рогозкина Н.Л. Количественное определение флавоноидов в цветках ромашки // Разработка, исследование и маркетинг новой фармацевтической промышленности: сборник научных трудов. Пятигорск, 2005. C. $44-46$.

22. Бубенчикова В.Н., Кондратова Ю.А. Разработка методик качественного и количественного определения флавоноидов в сырье ромашки аптечной // Кубанский научно-медицинский вестник. 2006. Т. 10. С. 19-21. 
23. Redaelli C., Formentini L., Santaniello E. Reversed-phase high-performance liquid chromatography analysis of apigenin and its glucosides in flowers of Matricaria chamomilla and chamomile extracts // Planta Med. 1981. Vol. 42. Pp. 288-292.

24. Zeković Z., Pekić B., Lepojević Ž., Petrović L. Chromatography in our investigations of chamomile (Matricaria chamomilla L.) // Chromatographia. 1994. Vol. 39. Pp. 587-590.

25. Raal A., Orav A., Pussa T., Valner C., Malmiste B., Arak E. Content of essential oil, terpenoids and polyphenols in commercial chamomile (Chamomilla recutita L. Rauschert) teas from different countries // Food Chem. 2012. Vol. 131. Pp. 632-638.

26. Mulinacci M., Romani A., Pinelli P., Vincieri F.F., Prucher D. Characterization of Matricaria recutita L. flower extract by HPLC-MS and HPLC-DAD // Chromatographia. 2000. Vol. 51. Pp. 301-307.

27. Weber B., Herrmann M., Hartmann B., Joppe H., Schmidt C.O., Bertram H.J. HPLC/MS and HPLC/NMR as hyphenated techniques for accelerated characterization of the main constituents in Chamomile (Chamomilla recutita $\mathrm{L}$. Rauschert) // Eur. Food Res. Technol. 2008. Vol. 226. Pp. 755-760.

28. Haghi G., Hatami A., Safaei A., Mehran M. Analysis of phenolic compounds in Matricaria chamomilla and its extracts by UPLC-UV // Res. Pharm. Sci. 2014. Vol. 9. Pp. 31-37.

29. Nováková L., Vildová A., Mateus J.P., Gonçalves T., Solich P. Development and application of UHPLC-MS/MS method for the determination of phenolic compounds in chamomile flowers and chamomile tea extracts // Talanta. 2010. Vol. 82. Pp. 1271-1280.

30. Полуденный Л.В., Сотник В.Ф., Хлапцев Е.Е. Эфирномасличные и лекарственные растения. М., 1979. 167 с.

31. Olennikov D.N., Kashchenko N.I. New acetylated glycosides of apigenin from the ligulate flowers of Matricaria chamomilla // Chem. Nat. Comp. 2016. Vol. 52. Pp. 992-995.

32. Руководство для предприятий фармацевтической промышленности (методические рекомендации). М., 2007. $192 \mathrm{c}$.

33. Matricaria flower. Art. No 01/2008:0404. European Pharmacopoeia 7.0. 2008. Pp. 1178-1179.

34. Grotewold E. The Science of Flavonoids. New York, 2006. 49 p.

35. Švehlíková V., Bennett R.N., Mellon F.A., Needs P.W., Piacente S., Kroon P.A., Bao Y. Isolation, identification and stability of acylated derivatives of apigenin 7-O-glucoside from chamomile (Chamomilla recutita [L.] Rauschert) // Phytochemistry. 2004. Vol. 65. Pp. 2323-2332.

36. Tschiersch K., Hoelzl J. Evidence and analytical procedure for acylated apigenin-7-glucosides // Pharm. Z. 1992. Vol. 137. Pp. 208-214.

Поступило в редакиию 10 июля 2016 г.

После переработки 23 сентября 2016 г.

Kashchenko N.I.*, Olennikov D.N. QUANTITATIVE ANALYSIS OF FLAVONOIDS IN CAMOMILE FLOWERS (MATRICARIA CHAMOMILLA L.) BY MICROCOLUMN HPLC-UV

Institute of General and Experimental Biology, Siberian Branch, Russian Academy of Science, ul. Sakh'yanovoy, 6, Ulan-Ude, 670047 (Russia),e-mail: ninkk@mail.ru

A reverse-phase microcolumn HPLC method with UV detection $(330 \mathrm{~nm})$ was developed for quantitative analysis of flavonoids of M. chamomilla flowers using a ProntoSIL-120-5-C18 AQ column $(60 \mathrm{~mm} \times 1 \mathrm{~mm} \times 5 \mu \mathrm{m})$, gradient elution system $0,2 \mathrm{M} \mathrm{LiClO}_{4} / 0,006 \mathrm{M} \mathrm{HClO}_{4}$-acetonitrile and cosmosiin as a reference compound. Optimal conditions for the hydrolytic process of flavonoids ( $\mathrm{KOH}$ concentration $0,25 \%$, extraction time $30 \mathrm{~min}$ ) and the parameters of flavonoids extraction (particle size $0,25 \mathrm{~mm}$, extraction temperature $60^{\circ} \mathrm{C}$, a single extraction step lasting $30 \mathrm{~min}$ at a ratio $1: 100$ ) were selected. Validation analysis showed that the proposed method is characterized by satisfactory metrological parameters. The limit of detection (LOD) and limit of quantification (LOQ) of cosmosiin were 84 and $255 \mathrm{ng} / \mathrm{ml}$, respectively. The accuracy for cosmosiin content levels $80-120 \%$ was less than $101,93-103,00 \%$. The method was used for the analysis of introduced and commercial samples of M. chamomilla flowers.

Keywords: Matricaria chamomilla L., Asteraceae, cosmosiin, flavonoids, microcolumn HPLC-UV.

\footnotetext{
* Corresponding author.
} 


\section{References}

1. Kurkin V.A., Sharova O.V., Afanas'eva P.V., Vel'miseva L.E., Fedorov A.V. Izvestiia Samarskogo nauchnogo tsentra RAN, 2012, vol. 14, pp. 2249-2252. (in Russ.).

2. Petruĺová-Poracká V., Repč́k M., Vilková M., Imrich J. Food Chem., 2013, vol. 141, pp. 54-59.

3. Ganzera M., Guggenberger M., Stuppner H., Zidorn C. Planta Med., 2008, vol. 74, pp. 453-457.

4. Caleja C., Barros M., Antonoi A.L., Ciric A., Barreira J.C.M., Sokovic M., Oliveira M.B.P.P., Santos-Buelga C., Ferreira I.C.F.R. J. Funct. Foods., 2015, vol. 16, pp. 114-124.

5. Kunde R., Isaak O. Planta Med., 1979, vol. 37, pp. 124-130.

6. $\quad$ Exner J., Reichling J., Becker H. Planta Med., 1980, vol. 39, pp. 219-219.

7. Xie X.-Y., Wang R., Shi Y.-P. Chem. Nat. Comp., 2014, vol. 50, pp. 910-911.

8. Redaelli C., Santaniello L.F. J. Chromatogr. A., 1981, vol. 209, pp. 110-112.

9. Glasl H. J. Chromatogr A., 1975, vol. 114, pp. 215-219.

10. Uteshev B.S., Laskova I.L., Afanas'ev V.A. Eksp. Klin. Farmakol., 1999, vol. 62, pp. 52-55.

11. Füller E., Blaschek W., Franz G. Planta Med., 1991, vol. 57, pp. 40-40.

12. Rezaeih R.A.P., Gurbuz B., Uyanik M., Rahimi A., Arslan N. J. Essent. Oil Bear. Pl., 2015, vol. 18, pp. $255-260$.

13. Miguel F.G., Cavalheiro A.H., Spinola N.F., Ribeiro D.L., Barcelos G.R.M., Antunes L.M.G., Hori J.I., MarqueleOliveira F., Rocha B.A., Berretta A.A. J. Evid. Based Complement. Altern. Med., 2015, vol. 2015, URL: https://www.ncbi.nlm.nih.gov/pmc/articles/PMC4573433/

14. Li K.-C., Ho Y.-L., Hsieh W.-T., Huang S.-S., Chang Y.-S., Huang G.-J. Int. J. Mol. Sci., 2015, vol. 16, pp. $1736-1754$.

15. Achterrath-Tuckermann U., Kunde R., Flaskamp E., Isaac O., Thiemer K. Planta Med., 1980, vol. 39, pp. 38-50.

16. Maschi O., Cero E.D., Galli G.V., Caruso D., Bosisio E., Dell'Agli M. J. Agric. Food Chem., 2008, vol. 56, pp. 5015-5020.

17. Gosudarstvennaia Farmakopeia SSSR. [State Pharmacopoeia of the USSR]. Moscow, 1990, vol. 2, pp. 237-238. (in Russ.).

18. Romashki tsvetki. Gosudarstvennaia Farmakopeia Respubliki Belarus'. [Chamomile flowers. State Pharmacopoeia of the Republic of Belarus]. Minsk, 2007, vol. II, pp. 412-413. (in Russ.).

19. Romashki tsvety. Gosudarstvennaia Farmakopeia Respubliki Kazakhstan. [Chamomile flowers. State Pharmacopoeia of the Republic of Kazakhstan]. Almaty, 2008, vol. 2, 724 p. (in Russ.).

20. United States Pharmacopeia. "Dietary supplements-Botanicals". The United States Pharmacopeial Convention, 2007, $901 \mathrm{p}$.

21. Pecherskaia L.G., Rogozkina N.L. Razrabotka, issledovanie i marketing novoi farmatsevticheskoi promyshlennosti: sbornik nauchnykh trudov. [Development, research and marketing of a new pharmaceutical industry: a collection of scientific papers]. Piatigorsk, 2005, pp. 44-46. (in Russ.).

22. Bubenchikova V.N., Kondratova Iu.A. Kubanskii nauchno-meditsinskii vestnik, 2006, vol. 10, pp. 19-21. (in Russ.).

23. Redaelli C., Formentini L., Santaniello E. Planta Med., 1981, vol. 42, pp. 288-292.

24. Zeković Z., Pekić B., Lepojević Ž., Petrović L. Chromatographia, 1994, vol. 39, pp. 587-590.

25. Raal A., Orav A., Pussa T., Valner C., Malmiste B., Arak E. Food Chem., 2012, vol. 131, pp. 632-638.

26. Mulinacci M., Romani A., Pinelli P., Vincieri F.F., Prucher D. Chromatographia, 2000, vol. 51, pp. 301-307.

27. Weber B., Herrmann M., Hartmann B., Joppe H., Schmidt C.O., Bertram H.J. Eur. Food Res. Technol., 2008, vol. 226, pp. 755-760.

28. Haghi G., Hatami A., Safaei A., Mehran M. Res. Pharm. Sci., 2014, vol. 9, pp. 31-37.

29. Nováková L., Vildová A., Mateus J.P., Gonçalves T., Solich P. Talanta, 2010, vol. 82, pp. 1271-1280.

30. Poludennyi L.V., Sotnik V.F., Khlaptsev E.E. Efirnomaslichnye i lekarstvennye rasteniia. [Aromatic and medicinal plants]. Moscow, 1979, 167 p. (in Russ.).

31. Olennikov D.N., Kashchenko N.I. Chem. Nat. Comp., 2016, vol. 52, pp. 992-995.

32. Rukovodstvo dlia predpriiatii farmatsevticheskoi promyshlennosti (metodicheskie rekomendatsii). [Guide for the pharmaceutical industry enterprises (guidelines)]. Moscow, 2007, 192 p. (in Russ.).

33. Matricaria flower. Art. No 01/2008:0404. European Pharmacopoeia 7.0, 2008, pp. 1178-1179.

34. Grotewold E. The Science of Flavonoids. New York, 2006, 49 p.

35. Švehlíková V., Bennett R.N., Mellon F.A., Needs P.W., Piacente S., Kroon P.A., Bao Y. Phytochemistry, 2004, vol. 65 , pp. 2323-2332.

36. Tschiersch K., Hoelzl J. Pharm. Z., 1992, vol. 137, pp. 208-214.

Received July 10, 2016

Revised September 23, 2016 
